ARTICLE

Received 20 Oct 2016 | Accepted 20 Feb 2017 | Published 20 Apr $2017 \quad$ DOl: 10.1038/ncomms15015

\title{
Metabolic labelling of the carbohydrate core in bacterial peptidoglycan and its applications
}

Hai Liang ${ }^{1, \star}$, Kristen E. DeMeester $^{1, \star}$, Ching-Wen Hou ${ }^{1}$, Michelle A. Parent ${ }^{2,3}$, Jeffrey L. Caplan ${ }^{3,4}$ \& Catherine L. Grimes ${ }^{1,3}$

Bacterial cells are surrounded by a polymer known as peptidoglycan (PG), which protects the cell from changes in osmotic pressure and small molecule insults. A component of this material, $N$-acetyl-muramic acid (NAM), serves as a core structural element for innate immune recognition of PG fragments. We report the synthesis of modifiable NAM carbohydrate derivatives and the installation of these building blocks into the backbone of Gram-positive and Gram-negative bacterial PG utilizing metabolic cell wall recycling and biosynthetic machineries. Whole cells are labelled via click chemistry and visualized using super-resolution microscopy, revealing higher resolution PG structural details and allowing the cell wall biosynthesis, as well as its destruction in immune cells, to be tracked. This study will assist in the future identification of mechanisms that the immune system uses to recognize bacteria, glean information about fundamental cell wall architecture and aid in the design of novel antibiotics.

\footnotetext{
${ }^{1}$ Department of Chemistry and Biochemistry, University of Delaware, 134 Brown Lab, Newark, Delaware 19716, USA. ${ }^{2}$ Department of Medical Laboratory Sciences, University of Delaware, Newark, Delaware 19716, USA. ${ }^{3}$ Department of Biological Sciences, University of Delaware, Newark, Delaware 19716, USA.

${ }^{4}$ Bioimaging Center, Delaware Biotechnology Institute, Newark, Delaware 19716, USA. * These authors contributed equally to this work. Correspondence and requests for materials should be addressed to C.L.G. (email: cgrimes@udel.edu).
} 
eptidoglycan (PG), a component of bacterial cell wall, is one of the essential polymers for life. Bacterial cells are surrounded by this material, which assists in bacterial cell division, maintenance of cell shape and small molecule recognition and signalling ${ }^{1,2}$. PG is composed of alternating monosaccharide units $\mathrm{N}$-acetyl glucosamine (NAG) and $\mathrm{N}$-acetyl muramic acid (NAM), with short peptide chains present on the muramic acid residue $^{3}$. These molecular building blocks can combine in a variety of ways to produce a range of macromolecular structures, with NAG and NAM remaining constant throughout all bacteria ${ }^{3}$. PG structures impact human health, as antibiotics are designed to target its destruction ${ }^{4}$, whereas the innate immune system senses and responds to bacteria via fragments of $\mathrm{PG}^{5}$.

The innate immune system, the first line of defense against pathogens ${ }^{6}$, must differentiate and control $\sim 39$ trillion bacteria that constitute the microbiome ${ }^{7}$. Commensal and pathogenic bacteria produce PG fragments, many of which contain the core glycan unit $\mathrm{NAM}^{8}$. The innate immune system utilizes a series of receptors, including Toll-like receptors and Nod-like receptors $^{9-11}$, which bind to fragments of $P G$, such as the synthetic fragments muramyl dipeptide (MDP) and muramyl tripeptide (MTP), to generate the proper immune response $\mathrm{e}^{12-14}$ (Fig. 1a). Moreover, misrecognition of PG fragments can lead to the development of inflammatory bowel disease, such as Crohn's disease, asthma and gastrointestinal cancers ${ }^{15,16}$. Information regarding the biological identity and the generation ${ }^{17,18}$ of these NAM-containing fragments, either via host or pathogen machinery, and the cellular location of these events is limited ${ }^{19-22}$. Tracking the biologically relevant NAM fragments of bacterial cell wall that are naturally produced proves challenging without a NAM-based set of molecular probes. To answer questions regarding both immune recognition and the three-dimensional (3D) architecture of bacterial cell walls, we developed the synthesis of the necessary PG building blocks, subsequent incorporation strategies and a method to label and visualize the glycan backbone directly.

To strategically develop a NAM-based labelling method, we first took inspiration from bacterial PG composition and biosynthesis. The biosynthesis of PG and its molecular intermediates have been known and well characterized since the late 1950s (refs 2,23). The PG polymer to be modified is highly crosslinked and its synthesis is conserved, involving more than ten distinct enzymatic steps (Fig. 1b). Motivation to utilize the biosynthetic machinery to tag this polymer was driven from enormous efforts and successes in in vivo labelling of macromolecular structures and PG. Pioneering work conducted by Bertozzi and Kiessling ${ }^{24}$ introduced bioorthogonal functionality into eukaryotic glycans. These studies showcased the power of glycoengineering and subsequent chemical manipulation in whole cells. We were interested in applying these fundamental principles to bacterial PG and gathered inspiration from previous efforts to label this polymer: unnatural amino acids including D-amino acid fluorophores and derivatives can be incorporated using metabolic machinery, cell wall targeting antibiotics can deliver probes and proteins embedded in the cell wall can be modified to include a fluorescent dye $\mathrm{e}^{25-36}$. Furthermore, efforts by Nishimura and
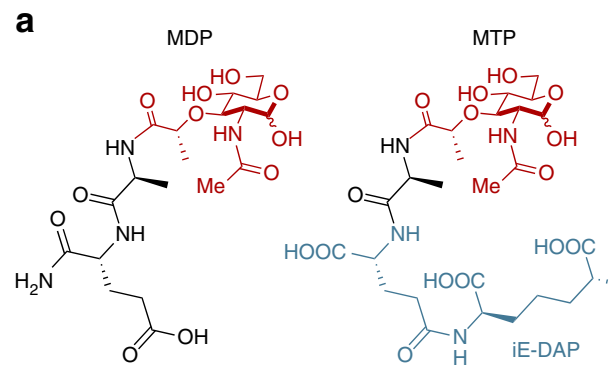

c

$$
\begin{aligned}
& \mathrm{HO}_{\mathrm{Me}^{2}} \geqslant \mathrm{O} \\
& X=\mathrm{OH} ; 1 \\
& \mathrm{ii} \longrightarrow X=\mathrm{OPO}_{2} \mathrm{H}_{2} ; 1 \mathrm{a}
\end{aligned}
$$
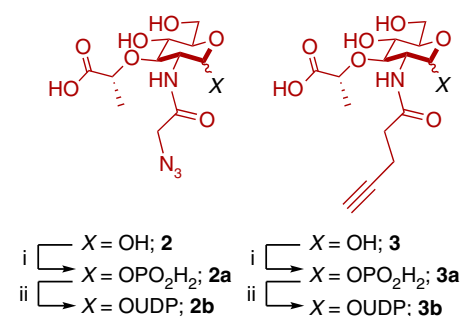
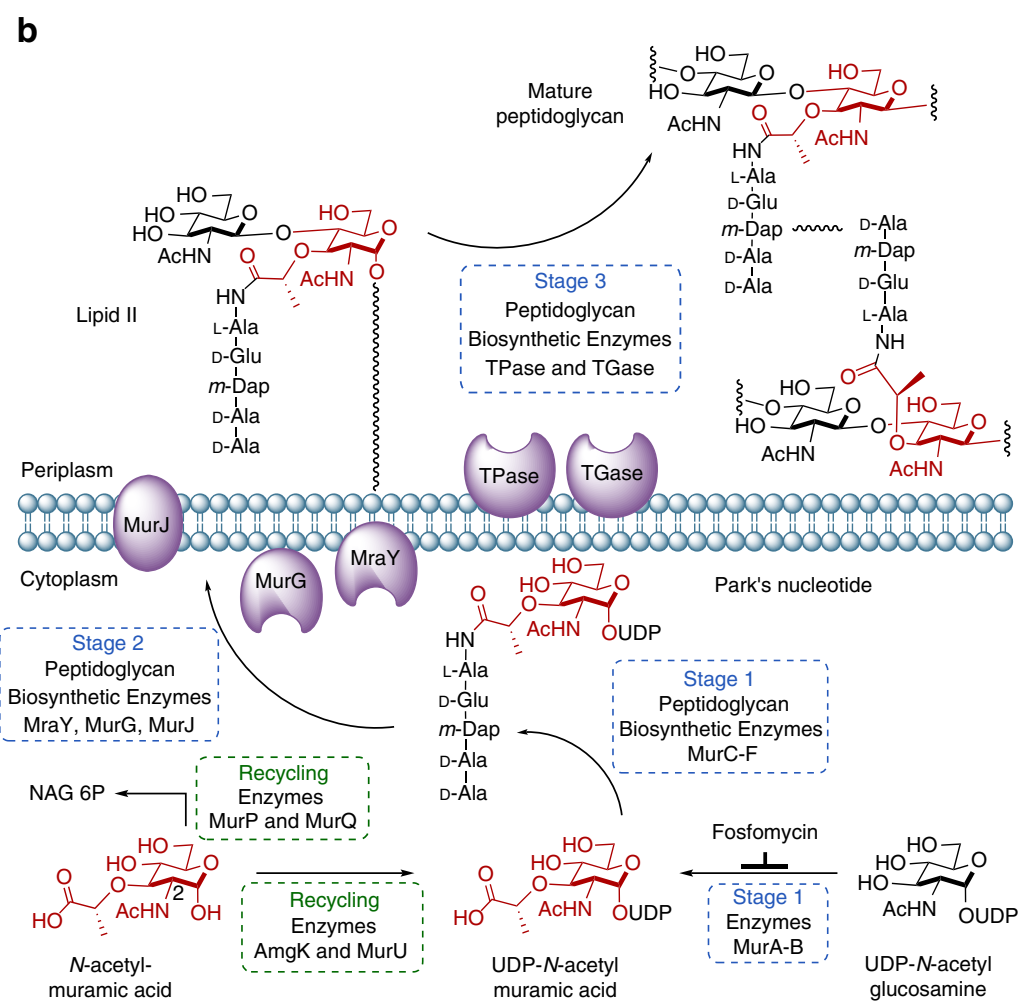

Figure 1 | Immunostimulatory PG fragments and use of bioorthogonal NAM derivatives in PG Biosynthesis. (a) Synthetic fragments MDP

( $\mathrm{N}$-acetylmuramic acid linked by its lactic acid moiety to the $\mathrm{N}$ terminus of an L-alanine $\mathrm{D}$-isoglutamine dipeptide) and MTP (MTP with the D-iso-glutaminediaminopimelic acid (iE-DAP) moiety shown in blue) of PG used to probe the innate immune response. (b) PG biosynthesis begins with the formation of UDP-MurNAc through MurA/B and UDP-NAG (UDP-GIcNAc). Recycling enzymes AmgK/MurU provide another route to synthesize UDP-MurNAc with NAM as the building block. NAM could be further metabolized into NAG 6-phosphate (NAG 6P) via enzymes MurP and MurQ. UDP-MurNAc is converted into Park's nucleotide through enzymes MurC-F. MraY links Park's nucleotide to the cell membrane where MurG then glycosylates this fragment to form Lipid II. MurJ transports Lipid II into the periplasmic space where transglycosylases (TGase) and transpeptidases (TPase) further cross-link these molecules to form the mature PG. (c) Bioorthogonal NAM (1) derivatives with azide (2) and alkyne (3) modifications: (i) AmgK and (ii) MurU. 
colleagues ${ }^{37}$ revealed that the NAG unit of PG could potentially be labelled at the 2- $N$ acetyl position in lactic acid bacteria. These elegant methods have proven useful in studying bacterial cell wall. However, current methods that label the terminal D-Ala residues of the peptide stems are subject to removal during PG remodelling and these terminal residues are not required for immune activation ${ }^{14}$. For example, MDP and MTP (Fig. 1a) do not contain a D-Ala residue. Moreover, extension of the peptide destroys the ability for the fragments to activate innate immune receptors in vitro ${ }^{13}$. However, the label at the NAM carbohydrate level will be retained in predicted innate immune agonist structures (MDP/MTP, Fig. 1a) $)^{5,13,14}$. Unfortunately, all of the aforementioned methods do not label on the NAM carbohydrate core of the PG polymer. To overcome this concern, we sought to install bioorthogonal functionality on the NAM carbohydrate backbone, which would increase the lifetime of the probe and allow the study of nascent polymer through metabolic labelling. $\mathrm{D}$-Ala probes can be incorporated by exchange reaction ${ }^{28}$ in mature cell wall, as well as through a biosynthetic route complicating efforts to measure sites of de novo PG synthesis. Furthermore, a NAM-based labelling strategy would allow for the selective incorporation of label into NAM residues, which are only found in bacterial $\mathrm{PG}^{5}$.

When designing the NAM-based probes, we were inspired by nature, as mycobacteria and Actinomycetes can modify the $2-N$ acetyl position of the NAM glycan to $N$-glycolyl via NAM hydroxylase ${ }^{38}$, revealing that unnatural structural features at the $\mathrm{N}$-acetyl position may be tolerated by the PG biosynthetic machinery. Although $N$-glycolylation has been responsible for an increase in immunogenicity ${ }^{39}$, we have recently shown that small modifications such as an azide and biotin, at the 2-N acetyl position do not have a significant effect on innate immune activation, specifically Nod2-dependent nuclear factor- $\kappa \mathrm{B}$ signalling ${ }^{40}$, indicating a tolerance of these bioorthogonal modifications that allow for manipulation at this position to study innate immune signalling. Here we present a new, complementary method to remodel and label the $2-\mathrm{N}$ position on the NAM residue and showcase its utility to visualize this essential structure in multiple organisms and monitor the fragmentation of PG after macrophage uptake.

\section{Results}

Synthesis of NAM derivatives and utilization by PG enzymes. The fundamental building blocks of bacterial cell wall are the glycans NAG and NAM. The latter is exclusively used as a PG building block (Fig. 1b). The NAM monosaccharide is introduced during the first committed step to bacterial cell wall biosynthesis with the formation of UDP- $N$-acetyl-muramic acid (UDP-MurNAc) (Fig. 1b). The bioorthogonal handle was installed at this intermediate. To circumvent the synthesis of the gram quantities of the UDP-MurNAc derivatives and complicated delivery strategies for the diphosphate moiety, we utilized cell wall recycling machinery, which is absent in Escherichia coli, but present in many bacterial species including Pseudomonas putida ${ }^{41}$. The recycling enzyme anomeric NAM/NAG kinase (AmgK) converts NAM 1 into MurNAc 1-phosphate 1a, which is then converted to UDP-MurNAc $\mathbf{1 b}$ by MurNAc $\alpha$-1-phosphate uridylyl transferase (MurU) (Fig. 1b,c). Intrigued by the functionality of these two enzymes, a modular synthetic strategy (Fig. 2 and Supplementary Methods) was implemented to build NAM derivatives $\mathbf{2}$ and $\mathbf{3}$ (Fig. 1c).

To synthesize the necessary amounts of NAM derivatives, we optimized our laboratory's recently reported synthesis of 2-azido MDP $^{40}$ (Fig. 2 and Supplementary Methods). First, we modified conditions $^{42}$ to produce high gram quantities of the 2-azido intermediate 4 from commercially available glucosamine $\mathrm{HCl}$ (Fig. 2 and Supplementary Methods). Using our established method for installation of the lactic acid moiety, intermediate 9 was prepared. Global deprotection unmasked the azide to reveal the secondary amine at the $2-N$ position of the NAM core in gram quantities. Material could be stored at this intermediate. The terminal carboxylic acid of $\mathbf{9}$ is poised to hydrogen bond to the free amine at position 2 (Fig. 2, compound 10), making coupling at the $2-N$ position challenging. Coupling conditions were developed to successfully synthesize NAM derivatives 2 and 3. These compounds were characterized (Supplementary Figs 21, 23,25 and 26 ) with an $18.5 \%$ overall yield from glucosamine $\mathrm{HCl}$.

With the NAM derivatives in hand, we assessed the substrate specificity of the recycling enzymes, AmgK and $\mathrm{MurU}^{41}$. We found that these enzymes were able to convert $\mathbf{2}$ and $\mathbf{3}$ with bioorthogonal modifications such as an azide or alkyne at the $2-\mathrm{N}$-acetyl position, to yield the respective UDP carbohydrate products $\mathbf{2} \mathbf{b}$ and $\mathbf{3 b}$, as confirmed by high-resolution liquid chromatography and mass spectrometry (HRLC/MS) (Supplementary Table 1). The ability to synthesize these unnatural NAM derivatives allowed for the demonstration that the recycling enzymes are promiscuous. From intermediates $\mathbf{2 b}$ and $\mathbf{3 b}$, we were also able to demonstrate that the biosynthetic enzymes (MurC-MurF, Fig. 1b) have relaxed substrate specificity as confirmed by HRLC/MS (Supplementary Table 1). If these enzymes did not tolerate the unnatural modifications, the ability to modify the NAM carbohydrate would not be possible. These data motivated us to investigate if the metabolic incorporation of NAM into the PG of whole bacterial cells was achievable.

NAM probes rescue bacteria from lethal dose of fosfomycin. Knowing that the recycling and stage one biosynthetic pathways are promiscuous, a cell-based assay to exclusively label the PG polymer was implemented (Fig. 3a). First, it is known that in E. coli PG metabolism, NAM sugars can be imported by a phosphotransferase system (MurP) and yield $\mathrm{N}$-acetylmuramic acid-6-phosphate (Fig. 1b) ${ }^{43}$. MurQ ${ }^{44}$, which is known as the only NAM-P etherase, can cleave off the D-lactic acid component of $\mathrm{N}$-acetylmuramicacid-6-phosphate to produce NAG-6 phosphate (Fig. 1b). The fate of NAG-6 phosphate will be divided into two parts: (1) incorporation into new bacterial PG, and (2) degradation and utilization as the carbon and energy source $^{44}$. To avoid potential metabolic incorporation of NAM probes through alternative catabolic pathways, an E. coli (MurQ)

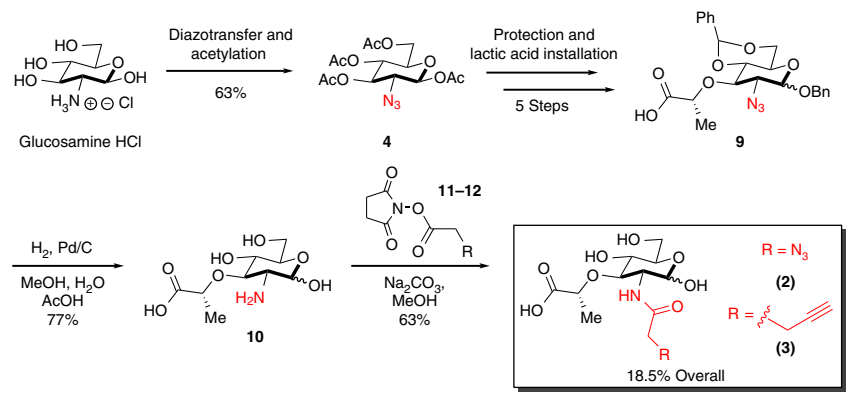

Figure 2 | Modular synthesis of bioorthogonal NAM derivatives. The azide was installed onto glucosamine $\mathrm{HCl}$ using a diazotransfer followed by acetylation to yield $\mathbf{4}$. Intermediate $\mathbf{4}$ was protected and modified over 5 steps: (i) hydrazine acetate; (ii) $\mathrm{COCl}_{2}$ followed by $\mathrm{AgCO}_{3}, \mathrm{AgOTf}$ and $\mathrm{BnOH}$; (iii) $0.5 \mathrm{M} \mathrm{NaOMe}$; (iv) $\mathrm{PhCH}(\mathrm{OMe})_{2}, \mathrm{pTSA}$; (v) $60 \% \mathrm{NaH}$, (s)-2-chloropropionic acid) to yield 9. Global deprotection via Pd/C hydrogenation produced $\mathbf{1 0}$. Followed by NHS coupling conditions, $\mathbf{2}$ and $\mathbf{3}$ are synthesized in $18.5 \%$ overall yield from the commercially available glucosamine $\mathrm{HCl}$ 
knockout strain was used (E. coli $\Delta \mathrm{MurQ})^{41}$. As amgK and $m u r U$ are from $P$. putida, not native to $E$. coli, expression vector (pBBR$\mathrm{KU})$ was introduced to construct the E. coli $\Delta \mathrm{MurQ}$ strains, which can express AmgK and MurU enzymes yielding E. coli $\Delta$ MurQ-KU (Methods).

Under the lethal concentration of fosfomycin, an antibiotic drug that can selectively inhibit the MurA enzyme ${ }^{45}$ (Fig. 1b), E. coli $\Delta$ MurQ-KU cells were unable to grow due to the inhibition of natural biosynthesis of UDP-MurNAc (Supplementary Fig. 1). Cell growth of E. coli $\Delta$ MurQ-KU can be restored in the presence of fosfomycin when cells were provided with an alternative way to synthesize UDP-MurNAc via the AmgK/MurU pathway and supplemented NAM sugars 1-3 (Fig. 1b,c and Supplementary Fig. 1). After $60-80 \mathrm{~min}$, it was observed that cell growth in the presence of 2 slowed. As the cell growth is dependent of the availability of PG building blocks, we added an additional dose of NAM sugars (1-2). This treatment resulted in restoration of cell growth rate (Supplementary Fig. 1b). Importantly, this cell growth analysis demonstrated that the NAM building blocks are able to sustain growth in the presence of a lethal dose of fosfomycin. This implies that the cell can build PG with bioorthogonal NAM carbohydrates, which can be modified and subsequently visualized.

Remodeling and labelling E. coli PG. To visualize PG, cells were grown in an optimized amount of either NAM derivatives 1-3. After incubation $(0.2 \%(\mathrm{w} / \mathrm{v})$ of NAM derivative, see Methods and Supplementary Figs 1a and 2), a subsequent Copper (I)catalysed azide-alkyne cycloaddition, also known as a 'click' reaction ${ }^{46}$, was applied to introduce a fluorophore into the remodelled PG polymer (see Methods). Cells supplemented with either $\mathbf{2}$ or $\mathbf{3}$ were successfully labelled with the corresponding alkyne or azide fluorophore $\mathrm{Cy} 5$ (AlkCy5 or AzCy5) or Rhodamine 110 (Alk488 or Az488) and visualized through structured illumination microscopy (SIM) ${ }^{47}$ (Fig. 3b, Supplementary Fig. 3a and Supplementary Movies 1 and 2). Only background labelling was observed when E. coli $\Delta$ MurQ-KU cells were supplemented with $\mathbf{1}$ and treated under click conditions (Supplementary Fig. 4a). Cells without recycling enzymes AmgK and MurU (E. coli $\Delta$ MurQ-pBBR), and E. coli DH5 $\alpha$ were not labelled with this method (Supplementary Fig. 4b,c, respectively). The data showed for the first time that carbohydrates could be directly visualized in the bacterial PG.

Efficiency/selectivity studies of labelled $E$. coli PG. We measured the cell population labelling efficiency of the NAM method through fluorescence activated cell sorting (Supplementary Fig. 3b-e). The percentage of the E. coli $\Delta$ MurQ-KU cell population that fluoresce after incorporation with either 2 or 3 followed by Copper (I)-catalysed azide-alkyne cycloaddition with the appropriate conjugated dye was shown to be over $87 \%$ of the total number of cells when compared with the control $\mathbf{1}$ subjected to the same click conditions (Supplementary Fig. 3b-e and Supplementary Table 4).

To demonstrate that these probes are in fact embedded in the PG, we took advantage of the fosfomycin antibiotic selection of the E. coli $\triangle$ MurQ-KU cells (Fig. 1b). With the MurA pathway blocked, the only known NAM source for the bacteria to build their new PG must come from the substrates we supplement to the cells. As previously described, E. coli $\Delta$ MurQ-KU cell growth could be restored and sustained in the presence of a lethal dose of fosfomycin and the modified sugars $\mathbf{2}$ or $\mathbf{3}$ (Supplementary Fig. 1). Further, fluorescence microscopy in combination with fluorescence activated cell sorting demonstrates the percent of the E. coli $\Delta$ MurQ-KU population that fluoresced decreased when cells were grown in the absence of fosfomycin (Fig. 1b and
Supplementary Fig. 5a,c). We observed a similar decrease in population labelling efficiency when labelled E. coli $\Delta$ MurQ-KU cells were treated with the cell wall digestive enzyme lysozyme, as this enzyme is known to specifically degrade PG and a decrease in labelling correlates with the decomposition of the polymer (Supplementary Fig. 5b,d).

To definitively show that the NAM probe was incorporated into PG, we desired MS evidence. Briefly, 488-labelled E. coli $\Delta \mathrm{MurQ}-\mathrm{KU}$ cells grown in the presence of $\mathbf{3}$ were treated with lysozyme (see Methods) and subjected to high-pressure liquid chromatography (HPLC) and high-resolution MS analyses (Supplementary Fig. 6a). We were able to identify and confirm potential mono-, di- and tetra-saccharide fragments of PG (compounds 13-17) tagged with the 488 fluorophore (Supplementary Fig. 6b,c), demonstrating successful NAM incorporation and fluorescence modification on the $E$. coli $\Delta$ MurQ-KU PG. PG fragments 13-17 were not found in E. coli $\Delta$ MurQ-KU cells supplemented with 1 under the same conditions. Importantly, the natural, untagged lysozyme product $\mathbf{1 8}$ was found in both treatments with $\mathbf{1}$ and $\mathbf{3}$, suggesting that PG was properly digested. The bioorthogonally tagged lysozyme product 19 was found solely in treatment with 3 (Supplementary Fig. $6 \mathrm{~b}, \mathrm{c})$, implying that $\mathbf{3}$ was successfully incorporated into whole cell PG and then digested. The amount of modified NAMs that can be incorporated into bacterial PG is limited by the ability of fosfomycin to completely inhibit MurA (Fig. 1b). If we assume complete inhibition and complete conversion of the click reaction (Fig. 3a), then after one doubling time, $50 \%$ of the PG would be labelled. After two doubling times, $75 \%$ of the PG would be labelled. However, the percent of incorporation could be lower due to incomplete fosfomycin inhibition. Furthermore, the MS data indicate that the click labeling percentage is not $100 \%$ (Supplementary Fig. 6c). Together, the cell growth assays with and without fosfomycin (Supplementary Fig. 5a,c), lysozyme digestion assay (Supplementary Fig. 5b,d) and MS data (Supplementary Fig. 6b,c) support the conclusion that the probes are efficiently labelling these bacterial populations and specifically incorporating into the bacterial PG.

Labelling of Gram-negative and Gram-positive bacterial PG. To demonstrate the utility of the method, the labelling strategy was implemented on additional Gram-negative bacterial strains. P. putida bacteria, which naturally have enzymes AmgK and MurU, and E. coli $\mathrm{DH} 5 \alpha$ cells with inducible AmgK and MurU (E. coli KU) were successfully labelled (Supplementary Fig. 7a,b). As a control, P. putida and E. coli KU cells supplemented with $\mathbf{1}$ were not labelled (Supplementary Fig. 7a,b). To further extend this labelling strategy to Gram-positive bacterial strains, a Bacillus subtilis strain containing the $a m g K$ and $m u r U$ gene cluster was constructed (B. subtilis 3A38$\mathrm{KU}$, Methods). After incubating with fosfomycin and compounds 2 or 3, B. subtilis 3A38-KU cells were successfully labelled (Supplementary Fig. 7c). Cells incubated with 1 were not labelled (Supplementary Fig. 7c). These preliminary data indicate that both Gram-positive and Gram-negative bacteria can be labelled with the NAM method. Given the conservation of PG biosynthesis across all bacteria $^{2}$, the labelling strategy has the potential to be applied to a broad range of bacterial strains, provided that the amgK and murU genes are present or can be introduced.

Super-resolution microscopy reveals features of PG. Although other methods have been reported to image PG through the introduction of fluorescent amino acids or utilizing fluorescent antibiotics, this method is the first to visualize the carbohydrate features of PG. The labelled bacteria were used to study the distribution and incorporation of the carbohydrate probe at the single molecule level. Cells pulsed with NAM derivatives for 
a

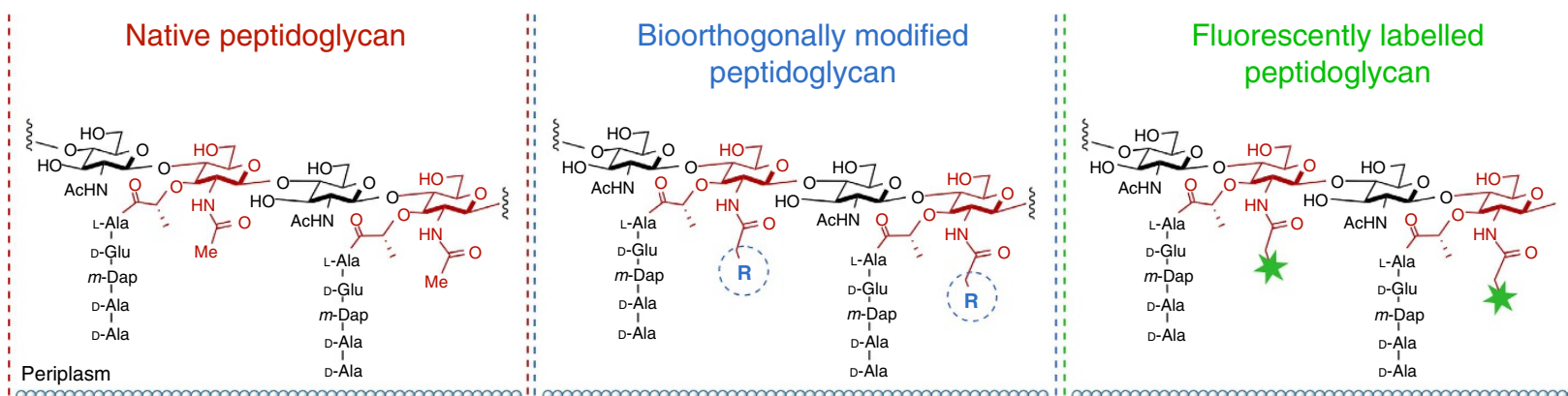

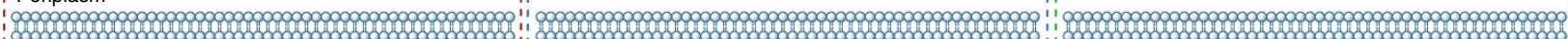
Cytoplasm

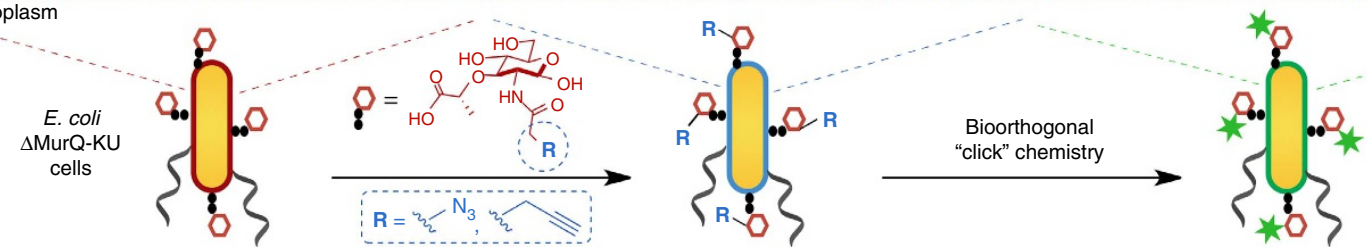

b
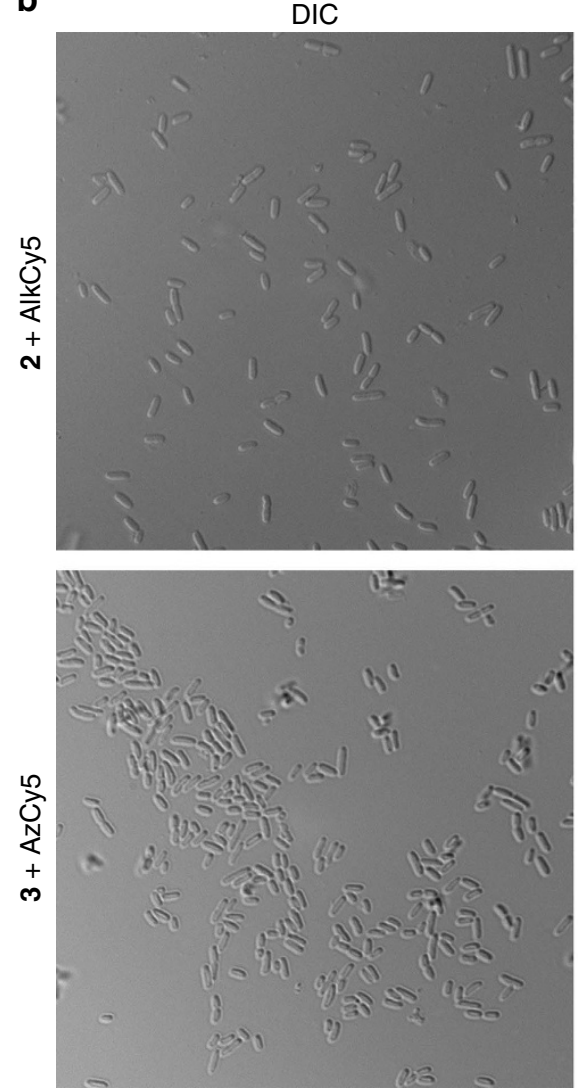

SIM
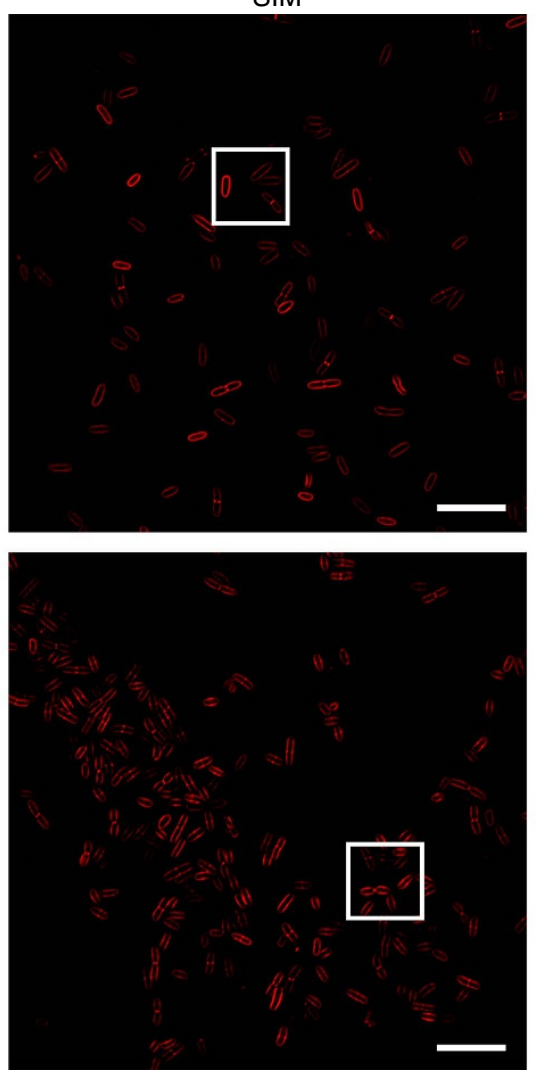
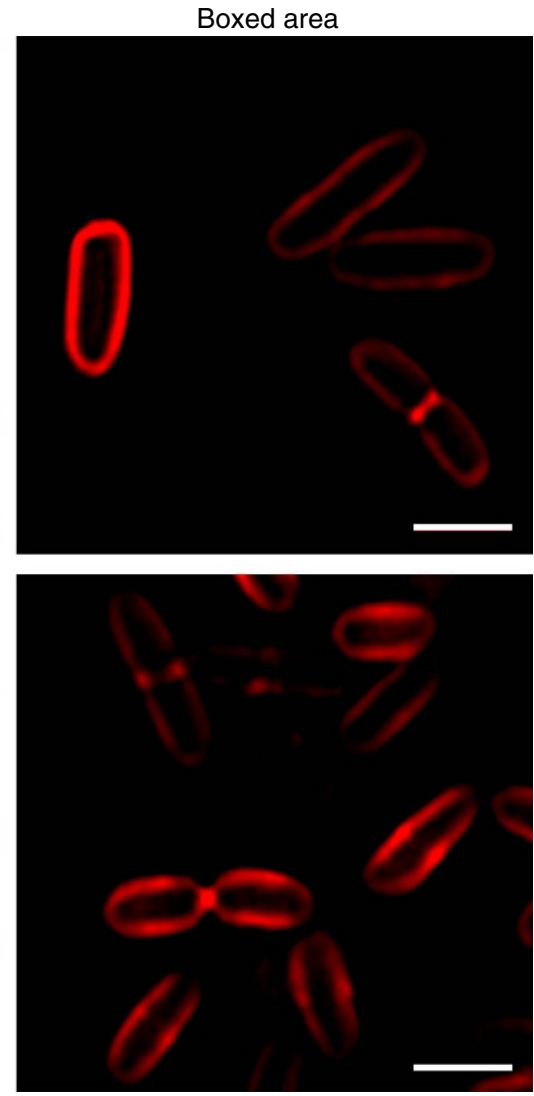

Figure 3 | Fluorescent labelling of E. coli DMurQ-KU cells. (a) Overall PG remodelling strategy. To survive fosfomycin inhibition, cells utilize the promiscuity of the recycling and biosynthetic enzymes for incorporation of bioorthogonal NAM building blocks into PG. Click chemistry affords fluorescence modification onto the NAM backbone of bacterial PG. (b) DIC and individual 2D images from super-resolution SIM Z-stacks of cells treated with $\mathbf{2}$ or $\mathbf{3}$ and clicked with Cy5 (red) (scale bars, $10 \mu \mathrm{m}$ for SIM and $2 \mu \mathrm{m}$ in the boxed area). The 2D and 3D renderings are provided in Supplementary Movies 1 and 2, respectively. Images are representative of a minimum of five fields viewed per replicate with at least two technical replicates and the experiment was conducted in over ten biological replicates.

different time intervals were observed using SIM (100-140 $\mathrm{nm}$ lateral resolution). At 15 min pulse length with 3 , the accumulation of fluorescent signal was low (Supplementary Fig. 8a). The amount and distribution of this label reached its maximum after $30 \mathrm{~min}$ pulse length (Supplementary Fig. 8b). Therefore, the
45 min pulse length with unnatural sugars was used to achieve the best labelling effect. Among these cells, we were able to visualize the glycans at a variety of stages in the bacterial cell division cycle (Fig. 4a). Interestingly, a clearly defined ring of septal PG was labelled and visualized (Fig. 3b, Supplementary Fig. 3a and 
Supplementary Movie 2). The location of this ring structure is consistent with what has been proposed for the Z-ring, a circular polymer of FtsZ (a homologue of tubulin), which serves as the scaffold of divisome assembly ${ }^{48}$. Thus, NAM probes can be used to label PG synthesis by both the cell elongation and cell division machineries, and will facilitate future experiments investigating the coordination between PG synthesis and cell division. This equatorial ring appears to shrink with the elongation of the bacterial cells and disappears once the cell division is nearly complete. The high incorporation of probe proved useful for visualizing global structural features of cell division.

To study the fluorescent PG at a higher resolution than SIM, E. coli $\triangle$ MurQ-KU cells pulsed with $\mathbf{3}$ for $15 \mathrm{~min}$ were imaged using 3D stochastic optical reconstruction microscopy (3DSTORM, $10-20 \mathrm{~nm}$ resolution $)^{49}$. The $15 \mathrm{~min}$ pulse length was chosen over the $45 \mathrm{~min}$ pulse length previously used for SIM, because the high incorporation saturated the finite details of cell wall architecture and shorter time points proved more useful for STORM. Moreover, a short time labelling period ( $15 \mathrm{~min}$, less than one doubling time (Supplementary Fig. 1)) proves more useful in the study of nascent PG biosynthesis, as the cells would just start to load and incorporate the probes. Evenly distributed fluorescent signals on the cell wall were observed as opposed to the internal cellular environment (Fig. 4b and Supplementary Movies 3 and 4). We were also able to visualize concentrated signals localized in the septal PG-ring with a diameter, from a constricting cell, estimated to be $570 \mathrm{~nm}$ (Fig. 4c,d), consistent with what was reported for the $Z$-ring using labelled Fts $Z^{50}$. From a selected region of the labelled cell, we were able to recognize a network of fluorescent carbohydrate strands that appeared to be interconnected (Supplementary Fig. 9a,b). The side view of this region showed that the fluorescent signal is on the surface of bacterial cells (Supplementary Fig. 9c). In some 3D-STORM images, ring-like structures (ranging from 90 to $180 \mathrm{~nm}$ ) in the PG were observed (Supplementary Fig. 9d-f and Supplementary Movie 5), indicating that nascent bacterial PG synthesis could follow the pattern of either a circular arrangement of carbohydrate residues or a closed intersecting network of PG chains. This pattern could result from a specific carbohydrate loading process during PG biosynthesis or the presence of protein complexes/lipid rafts. However, the pattern could also be a consequence of incomplete NAM incorporation or click fluorescent labelling (Supplementary Fig. 6). It is possible that smaller carbohydrate rings exist, as we have reached the resolution limit of STORM ${ }^{51}$. Importantly, the STORM control in which E. coli $\triangle$ MurQ-KU cells pulsed with 1 for $15 \mathrm{~min}$ and treated with AzCy5 did not show any substantial signal (Supplementary Fig. 9g).

Tracking of bacterial invasion and breakdown in macrophages. To determine whether this method would be useful in studying the interaction between NAM-based PG fragments and the innate immune system, NAM-labelled bacterial invasion of mammalian cells was studied. Bioorthogonally modified E. coli $\Delta$ MurQ-KU cells were incubated with J774 macrophage cells and were then subsequently labelled via click chemistry. SIM images confirm that the invasion of modified bacteria into the macrophage cytosol was successfully tracked, while unlabelled bacterial cells were not visualized (Fig. 5, Supplementary Fig 10a,b and Supplementary Movies 6 and 7). A population of macrophage cells contained deformed bacterial cells with released fluorescent fragments (Fig. 5b), which are confirmed to be inside the cells (Supplementary Fig. 10c and Supplementary Movie 8). As time increased, less whole bacterial cells were present inside the macrophage, while more fragments appeared (Supplementary Fig. 11a). We note that it is not clear whether these fragments are generated by macrophage digestion after invasion, or the normal break down of remodelled bacterial cells. When the remodelled
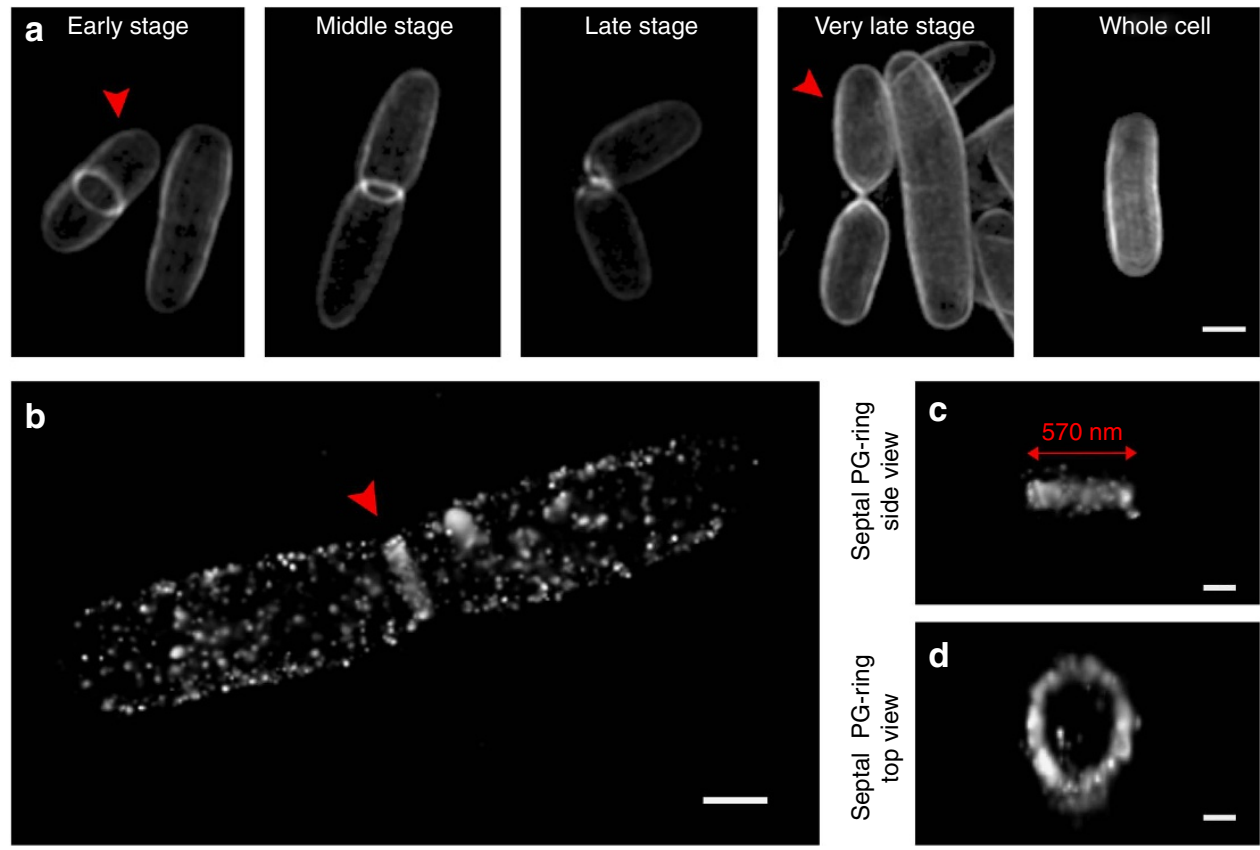

Figure 4 | Visualization studies of the carbohydrate probes' incorporation into PG. (a) SIM images of 488 labelled $E$. coli $\Delta$ MurQ-KU cells at different cell division stages compiled from separate cell sample populations (scale bar, $1 \mu \mathrm{m}$ ). Images are representative of a minimum of five fields viewed per replicate with at least two technical replicates and the experiment was conducted in at least three biological replicates. (b) Three-dimensional STORM image of cells treated with $\mathbf{3}$ and labelled with AzCy5, whole-cell view (scale bar, $0.5 \mu \mathrm{m}$ ). Two-dimensional and 3D renderings are provided in Supplementary Movies 3 and 4, respectively. From cell shown in (b,c) side view of Septal PG-ring and (d) top view of Septal PG-ring. All images were generated and distances were calculated within the Zen programme as described in Methods (scale bars, $0.2 \mu \mathrm{m}$ (c,d)). Images are representative of a minimum of two fields viewed per replicate with at least two technical replicates and the experiment was conducted in two biological replicates. 
bacterial cells were incubated in the DMEM medium in the absence of macrophage, a gradual decrease of bacterial cells was observed, implying that the cells could be degrading (Supplementary Fig. 11b), suggesting that remodelled cells cannot respond to some environmental stresses to the same degree as the wild-type cells. However, we note that the remodelled cells grow well in rich media (Supplementary Fig. 1). This labelling method allows selective tracking of the bacterial cell consumption and specific visualization of glycan units of PG upon macrophage infection, which can be used in future studies towards the identification and characterization of naturally occurring immunostimulatory NAM-containing PG fragments.

\section{Discussion}

We have developed a robust method to study the NAM carbohydrate backbone in the E. coli PG and applied this method to examine fundamental questions in bacterial cell wall structure and bacterial invasion. To begin the investigation, we desired a method to synthesize large quantities of NAM derivatives with bioorthogonal modifications at the $2-N$ position. The simplistic structure of the PG NAM unit can be quite deceiving and derivatives are not widely available. With few previous reports of manipulation at the $2-N$ position of this carbohydrate ${ }^{52-54}$, we sought to modify an existing method developed by our lab to access large quantities of bioorthogonally tagged NAMs. As a highlight, the robust azido protecting group displayed at the 2-N position of the glycan can be unmasked late in the synthesis, to allow for optimized acylation to install bioorthogonal modifications at the $2-\mathrm{N}$-acetyl position. These derivatives that were previously unavailable until now can be accessed in the necessary quantities. Armed with desired PG intermediates 2 and 3, a detailed analysis of the substrate specificity of the PG recycling and biosynthetic enzymes revealed that the conserved PG biosynthetic pathway is promiscuous, allowing for the installation of modified NAM residues. This in vitro analysis along with the reports of other successful PG labelling, allowed us to implement unnatural NAM building blocks as a tool to label whole cells.

We showed that PG from both Gram-positive and Gramnegative bacteria are able to be remodelled, labelled and visualized using this incorporation strategy. As E. coli and B. subtilis are the canonical model systems for Gram-negative and Gram-positive bacterium, the NAM labelling method should be applicable to a broad range of bacteria due to the conserved nature of the PG biosynthetic machinery. The data suggest that these labelled bacteria will also be useful in studying bacterial cell wall recycling in many bacterial strains. Interestingly, Mayer and colleagues ${ }^{55}$ recently reported that three Gram-positive bacterial strains, Staphylococcus aureus, B. subtilis and Streptomyces coelicolor that naturally have the murP and/or murQ genes, can use NAM in their cell wall recycling machinery. We propose that upon insertion of the $a m g K$ and murU genes into these bacterial strains, their PG would be remodelled and labelled with the NAM derivatives 2 and 3, as demonstrated in our B. subtilis 3A38-KU work.

The SIM images (Fig. 4a and Supplementary Movie 2) presented with the NAM labelling method agree with the literature precedent for whole-cell PG labelling via fluorescently labelled amino acids ${ }^{25-31}$. Patterns of evenly distributed fluorescent signal along the cell body and probe concentration at the septal division site appear similar, but using SIM we are able to view the carbohydrates in higher resolution. However,

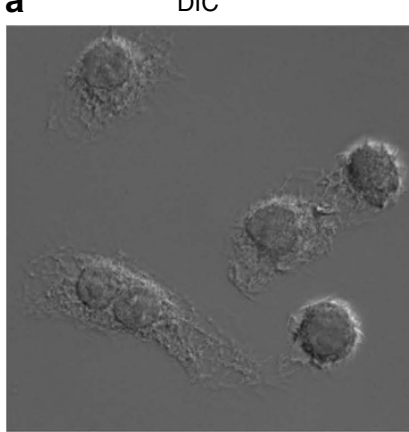

b

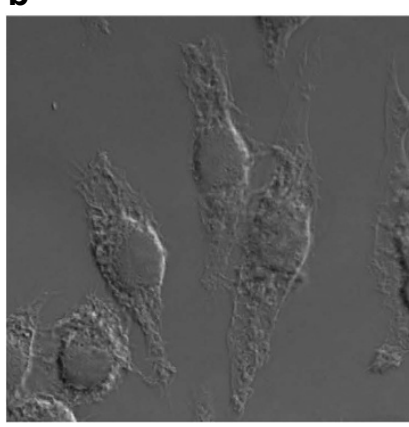

3D SIM
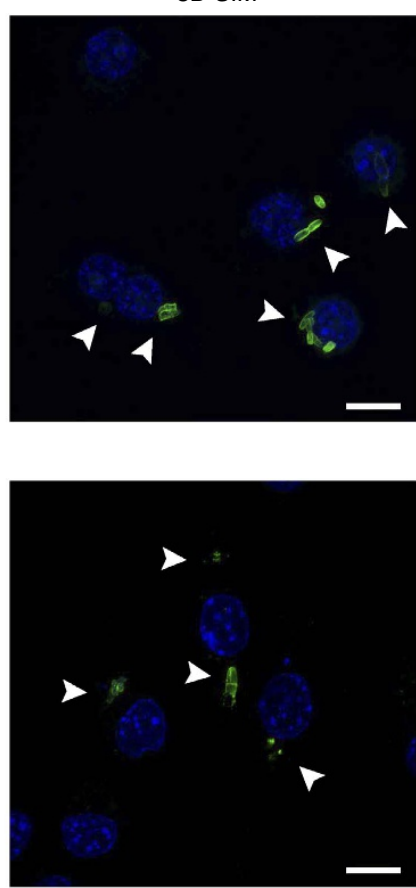

$\mathrm{DIC}+3 \mathrm{D}$ SIM
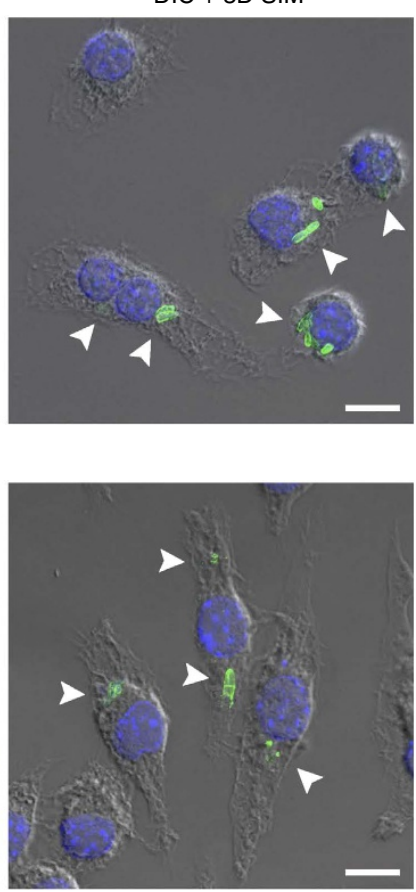

Figure $\mathbf{5}$ | $\mathbf{J 7 7 4}$ mouse macrophage cells invaded by remodeled $\boldsymbol{E}$. coli $\Delta$ MurQ-KU coli DMurQ-KU cells. (a) E. coli $\Delta$ MurQ-KU cells pre-treated with $\mathbf{3}$ for 45 min were then used to invade $\mathbf{J 7 4} 4$ cells for $1 \mathrm{~h}$. Cells were fixed and Az488 was clicked into remodelled bacterial PG (green). Whole bacterial cells were visualized as shown with white arrows. Cellular DNA was labelled with 4,6-diamidino-2-phenylindole (blue) (scale bar, $10 \mu \mathrm{m}$ ). (b) Cells treated as in a, in which deformed bacterial cells with released fluorescent fragments were visualized as shown with white arrows. Fluorescent images are maximum intensity projections of z-stacks. Three-dimensional renderings are provided in Supplementary Movies 6 and 8 . Images are representative of a minimum of three fields viewed per replicate with at least two technical replicates and invasion experiments were conducted in at least three biological replicates. 
helical wall patterns were not observed in the case of B. subtilis labelling as previously reported in fluorescently labelled ramoplanin and vancomycin $\mathrm{PG}^{32}$.

The super-resolution images of the NAM-labelled bacterial cells (Fig. 4 and Supplementary Movies 2-4) show that PG carbohydrate intermediates accumulate as a septal PG ring during cell division, providing preliminary evidence to the theory that PG biosynthesis and bacterial division are coordinated ${ }^{56}$. We suggest that these studies will be useful as an application to investigate the molecular details of the $Z$-ring. For example, colocalization of NAM probes and fluorescently labelled cell division enzymes may reveal the location and interaction between these enzymes and their associated NAM-containing carbohydrate intermediates. Although the Z-ring's structure has been characterized in detail at the protein level, the cell wall architecture, specifically at the carbohydrate level, is more challenging to address ${ }^{57}$.

A long-standing debate surrounds the orientation of the glycan chains in the bacterial cell wall ${ }^{1,32,51,58-60}$; models propose either a helical orientation or a linear glycan chain arrangement. For E. coli, the data presented in our study support the lack of a helical network at the carbohydrate level on the cell surface and proposes that the chains of glycans intersect to form a large circular network (Supplementary Fig. 9d-f and Supplementary Movie 5), with the helical structures derived from the peptide. Further experiments in which the PG is dual labelled (on both the carbohydrate and peptide) will be extremely valuable in understanding the way in which bacteria assemble this polymer.

The data also showed when remodelled E. coli was incubated with macrophages, not only were their engulfment by macrophages observed $21,22,30$, but also the breakdown of the bacterial PG was documented. These MDP-containing fragments could potentially be generated in two environments: (1) outside the cell during normal bacterial growth and division or (2) inside the cell during phagocytosis. Currently, MDP (Fig. 1a) is the standard bacterial PG fragment used by immunologists, as this synthetic fragment generates an immune response $\mathrm{S}^{, 12-14}$. The ability to install probes on the conserved NAM carbohydrate will be useful in identifying the biologically relevant fragments of PG. Using this method, we have already potentially identified larger fragments of bacterial PG such as mono-, di- and tetrasaccharide compounds (13-17, Supplementary Fig. 6a-c). We note that these fragments were identified using small culture volumes ( $100 \mathrm{ml}$, Methods), implying that the method will be sensitive enough to identify fragments produced during macrophage infection.

This work began with the construction of a scalable synthesis of bioorthogonal NAM derivatives. We then developed a method to metabolically label the NAM glycan backbone of $E$. coli, $P$. putida and B. subtilis utilizing the promiscuity of cell wall recycling and biosynthetic machineries in whole cells. The results reveal fundamental architectural details of the glycan chains of the PG and further enable us to track the engulfment and breakdown of bacteria in macrophages.

Commensal and pathogenic bacteria are believed to produce PG fragments containing the core glycan NAM unit. Misrecognition of these molecular calling cards by the innate immune system can lead to the development of inflammatory bowel disease. Importantly, a long-standing debate around the biological relevance of the immunoactive synthetic fragment MDP remains unclear due to a lack of NAM-based probes. The development of these NAM probes and a method to incorporate them into the carbohydrate backbone of PG is a critical progression toward answering these questions. Selective labelling of the NAM residue at the core of PG has advanced the way the production and destruction of the polymer is visualized and studied in the presence or absence of immune cells. It is a true complement to the methods that previously exist to label PG and when used in concert the entire PG could be illuminated.

\section{Methods}

Note. For synthetic procedures, please see Supplementary Methods.

Bacteria strains and plasmids. E. coli DH5 $\alpha$ and BL21 (DE3) strains were from the laboratory stock. E. coli murQ knockout stain was obtained from the Coli Genetic Stock Center, CGSC (number 9928). MurQ gene was replaced with the kanamycin resistant gene ${ }^{61}$. E. coli strains were grown in liquid or solid Luria broth (LB) medium, supplemented with appropriate antibiotics: carbenicillin $\left(100 \mu \mathrm{g} \mathrm{ml}^{-1}\right)$, kanamycin $\left(50 \mu \mathrm{g} \mathrm{ml}^{-1}\right)$ or chloramphenicol $\left(34 \mu \mathrm{g} \mathrm{ml}^{-1}\right)$. P. putida strain KT2440 was purchased from ATCC (ATCC number 47054). P. putida was grown in LB medium or M9 minimal medium with NAM $(0.2 \% \mathrm{w} / \mathrm{v})$ as the carbon source. B. subtilis $3 \mathrm{~A} 38$, a single point mutant of wild type B. subtilis strain 168 , which has increased competence ${ }^{62}$, was obtained from Bacillus Genetic Stock Center. This cell strain was cultured in liquid or solid LB medium. Plasmid pGEX-6P-1, which contains a glutathione $S$-transferase (GST) affinity tag gene, was used in protein expression and purification. Plasmid pBBR1MCS was used for exogenous genes expression in E. coli strains. Plasmid pDG1662 was used to integrate the cloned gene cluster into B. subtilis $3 \mathrm{~A} 38$ chromosome at the amyE locus, by a double-crossover recombination. Supplementary Information Table 2 shows a complete list of bacterial strains and plasmids used in this study. J774 macrophage cells were purchased from ATCC (catalogue number TIB-67), grown in DMEM supplemented with $10 \%$ heat-inactivated fetal bovine serum (Atlantic Biological) and $0.1 \%$ penicillin-streptomycin (Sigma-Aldrich) (unless otherwise noted) and routinely tested for mycoplasma (MycoAlert PLUS Mycoplasma Detection Kit, Lonza).

Construction of expression plasmids and bacterial strains. Full-length $P$. putida amgK and murU were PCR amplified from $P$. putida genome DNA with $5^{\prime}$-BamHI and $3^{\prime}$-XhoI restriction sites (primer sets are PpAmgK-For/PpAmgKRev and PpMurU-For/PpMurU-Rev, respectively). PCR products of amgK and mur $U$ were subsequently ligated into pGEX-6P-1 vector to generate pGEXPpAmgK plasmids and pGEX-PpMurU plasmids. E. coli murC, murD, murE and murF were PCR amplified from E. coli genome DNA. E. coli murC was inserted into pGEX-6P-1 vector with $5^{\prime}$-SalI and $3^{\prime}$-NotI restriction sites to generate pGEX-EcMurC plasmid (primer set is EcMurC-For/EcMurC-Rev). MurD and murE were inserted into pGEX-6P-1 with $5^{\prime}$-EcoRI and $3^{\prime}$-XhoI sites to get pGEX-EcMurD and pGEX-EcMurE plasmids (primer sets are EcMurD-For/ EcMurD-Rev, EcMurE-For/EcMurE-Rev, respectively). MurF was inserted into the same vector using $5^{\prime}$-BamHI and $3^{\prime}$-XhoI sites to get pGEX-EcMurF vector (primers are EcMurF-For/EcMurF-Rev). Exogenous AmgK and MurU expression plasmid pBBR-KU was constructed from pBBR1MCS vector, using the PCR product of $a m g K$ and murU cluster, and the $5^{\prime}$-KpnI and $3^{\prime}$-HindIII restriction sites (primer set: pBBRKU-For/pBBRKU-Rev). The forward primer contained about $40 \mathrm{bp}$ of the upstream region of $a m g K$ and $m u r U$ cluster of $P$. putida genome $\mathrm{DNA}^{41}$. All inserted genes were confirmed by sequencing with plasmid sequencing primers (for pGEX-6 P-1 vector, using primer set 5GEX/3GEX, for pBBR1MCS vector, using primer set M13F (-21)/M13R). A complete list of primer sequences used in this study is shown in Supplementary Table 3.

E. coli $\triangle \mathrm{MurQ}-\mathrm{KU}$ and $E$. coli KU cell lines were constructed by transforming pBBR-KU vector into $E$. coli $\Delta$ MurQ and $E$. coli DH5 $\alpha$ competent cells, respectively. Expression and function of AmgK and MurU enzymes were proved by a fosfomycinsusceptible agar diffusion assay. DNA of $a m g K$ and $m u r U$ gene cluster with $5^{\prime}-$ BamHI and $3^{\prime}$-HindIII restriction sites was cloned into pDG1662 plasmid to yield pDG-KU vector (primer set: pDGKU-For/pDGKU-Rev). pDG-KU vector was transformed into B. subtilis 3 A38-competent cells as described ${ }^{63}$. Transformants after genomic recombination were selected on LB plate with chloramphenicol $\left(5 \mu \mathrm{g} \mathrm{ml}^{-1}\right)$ and marked as B. subtilis $3 \mathrm{~A} 38-\mathrm{KU}$ strain. A complete list of primer sequences used in this study is shown in Supplementary Table 3.

Protein expression and purification. Reconstructed pGEX expression plasmids were transformed into BL21(DE3) competent cells. After transformation, a $10 \mathrm{ml}$ overnight BL21 cell culture was inoculated into $1 \mathrm{~L}$ fresh LB medium supplemented with $100 \mu \mathrm{g} \mathrm{ml}^{-1}$ carbenicillin antibiotics and incubated until $\mathrm{OD}_{600 \mathrm{~nm}}$ reached 0.6. The expression of GST-tagged proteins was induced with $1 \mathrm{mM}$ isopropyl-1-thio$\beta$-D-galactoside at $18{ }^{\circ} \mathrm{C}$ for $20 \mathrm{~h}$. Induced cells were harvested by centrifugation $(4,000 \mathrm{~g}, 30 \mathrm{~min})$ and resuspended in $20 \mathrm{ml} \mathrm{GST}$ lysis buffer $(150 \mathrm{mM} \mathrm{NaCl}, 50 \mathrm{mM}$ Tris, $2 \mathrm{mM}$ dithiothreitol (DTT) $\mathrm{pH} 7.0$, containing one protease inhibitor cocktail tablet from Roche). Cells were disrupted by two passes through a French Press at $10,000 \mathrm{psi}$ and centrifuged at $27,000 \mathrm{~g}$ for $2 \times 15 \mathrm{~min}$ to remove the cell debris. The supernatant was loaded onto a protein purification column with Glutathione Sepharose 4 Fastflow beads (GE Healthcare) and incubated at $4{ }^{\circ} \mathrm{C}$ for $1 \mathrm{~h}$. The flow through was released and column was washed five times with $20 \mathrm{ml}$ GST wash buffer $(500 \mathrm{mM}$ $\mathrm{NaCl}, 50 \mathrm{mM}$ Tris, $1 \mathrm{mM}$ DTT, $1 \mathrm{mM}$ EDTA pH 7.0). After the washes, $10 \mathrm{ml}$ GST elution buffer ( $150 \mathrm{mM} \mathrm{NaCl}, 50 \mathrm{mM}$ Tris, $1 \mathrm{mM}$ DTT and $1 \mathrm{mM}$ EDTA pH 7.0) was added with an appropriate amount of PreScission Protease. The column was incubated 
at $4{ }^{\circ} \mathrm{C}$ overnight and purified protein was collected. For long-term storage at $-20^{\circ} \mathrm{C}$, glycerol (20\% final concentration) was added into the protein solution.

Enzymatic reaction conditions. Activity and promiscuity of purified enzymes were studied in the enzymatic reactions. Products were analysed by HRLC/MS

(Supplementary Information). Conditions for each enzymatic reaction are as follows:

AmgK: to $100 \mathrm{mM}$ Tris buffer $\mathrm{pH} 7.9,2.0 \mathrm{mM}$ of one NAM derivative (1 (Sigma-Aldrich) or 2 and 3), $4.0 \mathrm{mM} \mathrm{ATP}$ and $1.0 \mathrm{mM} \mathrm{MgCl}_{2}$ was added $1.0 \mu \mathrm{g}$ purified $\mathrm{AmgK}$ enzyme per $100 \mu \mathrm{l}$ reaction sample. The reaction was incubated at room temperature for $2 \mathrm{~h}$ (ref. 41).

MurU: to $100 \mathrm{mM}$ Tris buffer $\mathrm{pH} 7.9,2.0 \mathrm{mM}$, 1a to 3a MurNAc-1P substrates, $4.0 \mathrm{mM}$ UTP (Sigma-Aldrich) and $0.5 \mathrm{U}$ of baker's yeast inorganic pyrophosphatase (Sigma-Aldrich) was added $1.0 \mu \mathrm{g}$ purified MurU enzyme per $100 \mu \mathrm{l}$ reaction sample. The reaction was incubated at $37^{\circ} \mathrm{C}$ for $3 \mathrm{~h}$ (ref. 41 ).

MurC: to $100 \mathrm{mM}$ Tris buffer $\mathrm{pH} 7.9,2.0 \mathrm{mM}$ of one UDP-MurNAc derivative (1b-3b), $15 \mathrm{mM}\left(\mathrm{NH}_{4}\right)_{2} \mathrm{SO}_{4}, 15 \mathrm{mM} \mathrm{MgCl}, 2.5 \mathrm{mM}$ 2-mercaptoethanol, $4.0 \mathrm{mM}$ L-Ala, $4.0 \mathrm{mM}$ ATP and $1.0 \mathrm{mM}$ DTT was added $1.0 \mu \mathrm{g}$ purified MurC enzyme per $100 \mu \mathrm{l}$ reaction sample. The reaction was incubated at room temperature for $3 \mathrm{~h}$ (ref. 64)

MurD: to $100 \mathrm{mM}$ Tris buffer $\mathrm{pH} 7.9,2.0 \mathrm{mM}$ of one UDP-MurNAc-L-Ala derivative (1c-3c, Supplementary Information), $4.0 \mathrm{mM} \mathrm{D}$-Glu, $4.0 \mathrm{mM}$ ATP and $2.0 \mathrm{mM} \mathrm{MgCl}_{2}$ was added $1.0 \mu \mathrm{g}$ purified MurD enzyme per $100 \mu \mathrm{l}$ reaction sample. The reaction was incubated at room temperature for $3 \mathrm{~h}$ (ref. 65).

MurE reaction: to $100 \mathrm{mM}$ Tris buffer $\mathrm{pH} 7.9,2.0 \mathrm{mM}$ of one UDP-MurNAc-LAla-D-Glu derivative (1d-3d, Supplementary Information), $4.0 \mathrm{mM}$ meso-DAP (Sigma-Aldrich), $4.0 \mathrm{mM} \mathrm{ATP,} 2.0 \mathrm{mM} \mathrm{MgCl} 2$ and $1.0 \mathrm{mM}$ DTT was added $1.0 \mu \mathrm{g}$ purified MurE enzyme per $100 \mu \mathrm{l}$ reaction sample. The reaction was incubated at room temperature for $3 \mathrm{~h}$ (ref. 66).

MurF reaction: to $100 \mathrm{mM}$ Tris buffer $\mathrm{pH} 7.9,2.0 \mathrm{mM}$ of one UDP-MurNAc-LAla-D-Glu-m-DAP derivative (1e-3e, Supplementary Information), $4.0 \mathrm{mM}$ D-Ala-D-Ala (Sigma-Aldrich), $4.0 \mathrm{mM}$ ATP and $2.0 \mathrm{mM} \mathrm{MgCl}_{2}$ was added $1.0 \mu \mathrm{g}$ purified MurF enzyme per $100 \mu \mathrm{l}$ reaction sample. The reaction was incubated at room temperature for $3 \mathrm{~h}$ (ref. 67).

Bacterial cell growth curve study. Exponentially growing E. coli $\Delta \mathrm{MurQ}-\mathrm{KU}$ cells were diluted to $\mathrm{OD}_{600 \mathrm{~nm}} 0.04 .1 \mathrm{ml}$ of cell culture was incubated in $5 \mathrm{ml}$ sterilized tubes. $0.2 \%\left(\mathrm{w} / \mathrm{v}\right.$ ) sugar substrates $1-3$ and $200 \mathrm{\mu g} \mathrm{ml}^{-1}$ fosfomycin were added into experimental samples, and water was used as control. Three replicates samples were used for each study. Cells were incubated at $37^{\circ} \mathrm{C}$ and $\mathrm{OD}_{600 \mathrm{~nm}}$ was measured (Eppendorf 6136) and recorded every $20 \mathrm{~min}$ for $140 \mathrm{~min}$ in total. When additional dosage of NAM substrates 1-3 was added, they were added at $0.2 \%$ $(w / v)$. Cell growth curves were formulated with GraphPad Prism 6 software

Bacterial cell wall remodelling and labelling. Overnight pre-cultured E. coli $\Delta$ MurQ-KU cells, $P$. putida cells or B. subtilis 3A38-KU cells were inoculated into fresh LB medium and were incubated until the $\mathrm{OD}_{600 \mathrm{~nm}}$ was about $0.600 .1 \mathrm{ml}$ of cells were collected by centrifugation at $6,000 \mathrm{~g}$ for $5 \mathrm{~min}$. E. coli $\Delta \mathrm{MurQ}-\mathrm{KU}$ and $B$. subtilis $3 \mathrm{~A} 38-\mathrm{KU}$ cells were resuspended in $200 \mu \mathrm{LB}$ medium and $P$. putida cells were resuspended in same amount of M9 minimal medium with $0.2 \%(\mathrm{w} / \mathrm{v})$ Glucose. One of the NAM sugars 1-3 $[0.2 \%(\mathrm{w} / \mathrm{v})]$, and $200 \mu \mathrm{g} \mathrm{ml}^{-1}$ fosfomycin were added into both cell samples, whereas $1 \mathrm{mM}$ isopropyl-1-thio- $\beta$-D-galactoside was only added to the E. coli cell samples. All cells were incubated at $37^{\circ} \mathrm{C}$ for time ranging from 15 to $60 \mathrm{~min}$, depending on the desired experiments. Cells were then collected $(6,000 \mathrm{~g}, 5 \mathrm{~min})$ and washed with $500 \mu \mathrm{l} 1 \times$ PBS buffer twice. Cells were resuspended in $200 \mu \mathrm{l}$ 1:2 tert-butanol:water to prepare for the click reaction. To the bioorthogonally tagged bacterial cells was sequentially added $1 \mathrm{mM} \mathrm{CuSO}_{4}$ solution, $128 \mu \mathrm{M}$ Tris[(1-benzyl-1H-1,2,3-triazol-4-yl)methyl]amine, $1.2 \mathrm{mM}$ freshly prepared $(+)$ - sodium (L) ascorbate (Sigma-Aldrich) and either $20 \mu \mathrm{M}$ of Az488 or Alk488, or $2 \mu \mathrm{M} \mathrm{AzCy5}$ or AlkCy5 (Sigma Aldrich, Supplementary Note). Cells were incubated at room temperature for $30 \mathrm{~min}$ (ref. 30). Cells were washed four times with $1 \times$ PBS. The cells were resuspended in $100 \mu l 1 \times$ PBS and prepared for imaging. All other E. coli strains were remodelled and labelled as E. coli $\Delta$ MurQ-KU cells.

Structured illumination microscopy. Cover glasses (Zeiss; $22 \mathrm{~mm} \times 22 \mathrm{~mm}$ ) were treated with $0.1 \mathrm{mg} \mathrm{ml}^{-1}$ poly-L-lysine (Sigma-Aldrich) for $3 \mathrm{~h}$ at room temperature. Cover glasses were washed three times with deionized (DI) water and were air-dried at room temperature. Ten to twenty microlitres of labelled cells were loaded onto the centre of cover glass and incubated at room temperature for $30 \mathrm{~min}$, to allow cell adherence. Cells were rinsed three times with $1 \times \mathrm{PBS}$ and fixed with $500 \mu \mathrm{l}$ of $4 \%$ paraformaldehyde (stored under $\mathrm{N}_{2}$ ) at $4{ }^{\circ} \mathrm{C}$ for $30 \mathrm{~min}$. Cover glasses with fixed cells were washed with $1 \times$ PBS for three times and laid onto glass slides (Fisher Scientific) with $5 \mu$ l of ProLong Diamond Antifade Mountants (ThermoFisher) to cover the whole cover glass. SIM images were taken on a Zeiss Elyra PS.1 microscope with Plan-Apochromat $\times 63 / 1.4$ Oil differential interference contrast (DIC) M27 objective. Excitation of Az488/Alk488 and $\mathrm{AzCy} 5 / \mathrm{AlkCy} 5$ were achieved with 488 and $642 \mathrm{~nm}$ laser excitations, respectively. Camera exposure time was set to $100.0 \mathrm{~ms}$ and the raw data contained 5 rotations and $0.110 \mu \mathrm{m} z$-stack interval. SIM images were reconstructed from raw data with
Carl Zeiss ZEN 2012. Processing and filtering settings were kept constant and image intensity was preserved with the raw image scale option in Zen 2012. Zen 2012 or Zen 2 software was used to generate two-dimensional (2D) and 3D images, respectively. Measurements were made in Zen 2012 using the line measurement tool from individual XY slices or YZ cross-sectional views.

Three-dimensional STORM imaging. Cells were pulsed with 3 for $15 \mathrm{~min}$ and then labelled as described above with $\mathrm{AzCy} 5$ and fixed to poly-L-lysine-coated cover glass-bottom dishes (Matek, Inc). An oxygen scavenging buffer (10\% glucose (w/v; Sigma-Aldrich 49163-100 ml), $62.5 \mu \mathrm{g} \mathrm{ml}^{-1}$ Catalase (Sigma-Aldrich C3115-50MG), $600 \mu \mathrm{g} \mathrm{ml}^{-1}$ Glucose Oxidase (Sigma-Aldrich G0543-50KU)) and imaging buffer containing $10 \mathrm{mM}$ Cysteamine hydrochloride (MEA; Sigma-Aldrich

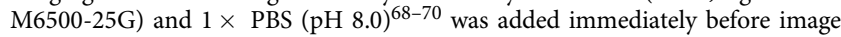
acquisition. Three-dimensional STORM images were taken on the Zeiss Elyra PS.1 microscope with a Plan-Apochromat $\times 63 / 1.4$ Oil DIC M27 objective using $642 \mathrm{~nm}$ laser excitation and a $655 \mathrm{~nm}$ long-pass filter. Camera exposure time was set to $18 \mathrm{~ms}$ with an electron-multiplying charge-coupled device gain of 300 . Raw data were processed with Carl Zeiss ZEN 2 and molecules were filtered to $10 \mathrm{~nm} \times 10 \mathrm{~nm} \times 60 \mathrm{~nm}(\mathrm{XYZ})$ localization precision. Zen 2012 or Amira 6 software was used to generate $2 \mathrm{D}$ and $3 \mathrm{D}$ images.

Flow cytometry. Bacteria labelled with either 488 or Cy5 were washed and resuspended in $100 \mu 11 \times$ PBS. Flow cytometry was performed on an Accuri C6 instrument, with DI water back flushing before and after each sample. Samples were vortexed for $10 \mathrm{~s}$ before each run. Cells $(100,000)$ were analysed for each sample in triplicate and fluorescence intensities for R1-gated samples were measured. Histograms of fluorescence intensities (height) were generated and overlaid. Statistical data for mean FL-4H and mean FL-1H supplied in Supplementary Table 4 based on equal population number. The s.d. generated from technical triplicates.

PG digestions and HPLC/MS analysis. Two $100 \mathrm{ml}$ samples of E. coli $\triangle \mathrm{MurQ}$ $\mathrm{KU}$ cells were remodelled with 3 and then fluorescently labelled with Az-488 via click chemistry as described above. The same amount of cells was treated with $\mathbf{1}$ as control. All the samples were washed four times with $12 \mathrm{ml}$ of $1 \times \mathrm{PBS}$ and finally stored as a dry pellet at $-80^{\circ} \mathrm{C}$. Labelled and control cells were confirmed by microscopy as above. To digest the PG, the cell pellets were resuspended in $5 \mathrm{ml}$ of digestion buffer $(25 \mathrm{mM} \mathrm{NaCl}, 50 \mathrm{mM}$ Tris, $2 \mathrm{mM}$ EDTA pH 7.9), then freshly prepared lysozyme was added into each sample $\left(1 \mathrm{mg} \mathrm{ml}^{-1}\right.$ of the final concentration). Samples were incubated with agitation at $37^{\circ} \mathrm{C}$ for 3 days, with the addition of $1 \mathrm{mg} \mathrm{ml}^{-1}$ freshly prepared lysozyme every $\sim 24 \mathrm{~h}$. Digested samples were centrifuged for $5 \mathrm{~s}$ and the supernatant was filtered through Amicon Ultra $3 \mathrm{~K}$ Filter Devices and lyophilized into a green/blue gel-like material, which was then dissolved in a minimal amount of DI water $(20 \mu \mathrm{l})$. The samples were resolved on an Acquity UPLC BEH C18 column $2.1 \times 50 \mathrm{~mm}$ (Waters) using a Dionex UHPLC coupled to a Q-Exactive Orbitrap (Thermo Fisher Scientific). The LC method was a $0.5 \mathrm{ml} \mathrm{min}^{-1}$ linear gradient starting from $0 \% \mathrm{~A}$ to $50 \% \mathrm{~B}$ in $4 \mathrm{~min}$. Eluent A was $0.1 \%$ formic acid in water and Eluent B was $0.1 \%$ formic acid in acetonitrile. The absorbance of the eluting peaks was measured at $505 \mathrm{~nm}$ and further subjected high-resolution mass analysis on the Q-Exactive. All data were processed and analysed on a Thermo Xcalibur Qual Browser. All species not only showed the expected mass within \pm 5 p.p.m., but also the correct isotopic pattern.

Macrophage invasion and immunostaining. The day before seeding the cells, sterile cover glasses (Fischer Scientific, catalogue number 12-545-80) were coated with $500 \mu \mathrm{l}$ of $0.1 \mathrm{mg} \mathrm{ml}^{-1}$ poly-L-ornithine (Sigma-Aldrich) in 24-well plates overnight. One day before bacterial invasion, the poly-L-ornithine was removed and the cover glasses were washed with DMEM medium without antibiotics twice. J774 macrophages (provided by M. Parent, purchased ATCC catalogue number TIB-67) were seeded on these cover glasses in 24-well plates with DMEM medium (Methods) without antibiotics (penicillin-streptomycin) at a density of $1 \times 10^{5}$ cells per well. For invasion with remodelled $E$. coli $\Delta$ MurQ-KU cells, bacteria were grown and remolded with modified NAM derivative 3 as described above. The bacteria $\left(5 \times 10^{5}\right.$ cells $)$ were added to the macrophage for different time lengths 20 , 40, 60 and $80 \mathrm{~min}$. After incubation, the medium was removed and fresh medium with gentamicin $(1: 1,000)$ was added to kill extracellular bacteria for $30 \mathrm{~min}$ at $37^{\circ} \mathrm{C}$. After $30 \mathrm{~min}$, the medium was removed and cells were rinsed twice with $1 \times$ PBS at room temperature. Cells were fixed with $4 \%$ formaldehyde in $1 \times$ PBS for $10 \mathrm{~min}$ at room temperature. Cells were rinsed with $1 \times$ PBS and then permeabilized with $1 \%$ Triton X-100 for $10 \mathrm{~min}$ at room temperature. Fixed cells were then rinsed in $1 \times$ PBS containing 3\% BSA and $0.1 \%$ Triton X-100 for $3 \times 5$ min. After rinsing cells in $1 \times$ PBS, the click reaction was performed as described above in $1 \times$ PBS with $0.01 \%$ BSA and $0.1 \%$ Triton X-100 for $30 \mathrm{~min}$. After $30 \mathrm{~min}$, the cells were rinsed in $1 \times$ PBS and then washed in $1 \times$ PBS containing $3 \%$ BSA and $0.1 \%$ Triton X-100 for $5 \times 8$ min. The cells were mounted on glass slides with 4,6-diamidino-2-phenylindole (Invitrogen) and ready for imaging. 
Data availability. The data that support the findings of this study are available from the corresponding author upon request.

\section{References}

1. Holtje, J. V. Growth of the stress-bearing and shape-maintaining murein sacculus of Escherichia coli. Microbiol. Mol. Biol. Rev. 62, 181-203 (1998).

2. Schleifer, K. H. \& Kandler, O. Peptidoglycan types of bacterial cell walls and their taxonomic implications. Bacteriol. Rev. 36, 407-477 (1972).

3. Rogers, H. J. Peptidoglycans (mucopeptides): structure, function, and variations. Ann. N. Y. Acad. Sci. 235, 29-51 (1974).

4. Walsh, C. Molecular mechanisms that confer antibacterial drug resistance. Nature 406, 775-781 (2000).

5. Strominger, J. L. Bacterial cell walls, innate immunity and immunoadjuvants. Nat. Immunol. 8, 1269-1271 (2007)

6. Janeway, Jr. C. A. \& Medzhitov, R. Innate immune recognition. Annu. Rev. Immunol. 20, 197-216 (2002).

7. Sender, R., Fuchs, S. \& Milo, R. Revised estimates for the number of human and bacteria cells in the body. PLoS Biol. 14 e1002533 1-21 (2016).

8. Mackey, D. \& McFall, A. J. MAMPs and MIMPs: proposed classifications for inducers of innate immunity. Mol. Microbiol. 61, 1365-1371 (2006).

9. Brubaker, S. W., Bonham, K. S., Zanoni, I. \& Kagan, J. C. Innate immune pattern recognition: a cell biological perspective. Annu. Rev. Immunol. 33, 257-290 (2015).

10. Ting, J. P., Duncan, J. A. \& Lei, Y. How the noninflammasome NLRs function in the innate immune system. Science 327, 286-290 (2010).

11. Chen, G., Shaw, M. H., Kim, Y. G. \& Nunez, G. NOD-like receptors: role in innate immunity and inflammatory disease. Annu. Rev. Pathol. 4, 365-398 (2009).

12. Ellouz, F., Adam, A., Ciorbaru, R. \& Lederer, E. Minimal structural requirements for adjuvant activity of bacterial peptidoglycan derivatives. Biochem. Biophys. Res. Commun. 59, 1317-1325 (1974).

13. Girardin, S. E. et al. Peptidoglycan molecular requirements allowing detection by Nod1 and Nod2. J. Biol. Chem. 278, 41702-41708 (2003).

14. Inohara, N. et al. Host recognition of bacterial muramyl dipeptide mediated through NOD2. Implications for Crohn's disease. J. Biol. Chem. 278, 5509$5512(2003)$.

15. Geddes, K., Magalhaes, J. G. \& Girardin, S. E. Unleashing the therapeutic potential of NOD-like receptors. Nat. Rev. Drug Discov. 8, 465-479 (2009).

16. Thaiss, C. A., Zmora, N., Levy, M. \& Elinav, E. The microbiome and innate immunity. Nature 535, 65-74 (2016).

17. Hasegawa, M. et al. Differential release and distribution of Nod1 and Nod2 immunostimulatory molecules among bacterial species and environments J. Biol. Chem. 281, 29054-29063 (2006).

18. Humann, J. \& Lenz, L. L. Bacterial peptidoglycan degrading enzymes and their impact on host muropeptide detection. J. Innate Immun. 1, 88-97 (2009).

19. Dziarski, R. Recognition of bacterial peptidoglycan by the innate immune system. Cell Mol. Life Sci. 60, 1793-1804 (2003).

20. Shimada, T. et al. Staphylococcus aureus evades lysozyme-based peptidoglycan digestion that links phagocytosis, inflammasome activation, and IL-1beta secretion. Cell Host Microbe 7, 38-49 (2010).

21. Herskovits, A. A., Auerbuch, V. \& Portnoy, D. A. Bacterial ligands generated in a phagosome are targets of the cytosolic innate immune system. PLoS Pathog. 3 e51 431-443 (2007)

22. Wyckoff, T. J., Taylor, J. A. \& Salama, N. R. Beyond growth: novel functions for bacterial cell wall hydrolases. Trends Microbiol. 20, 540-547 (2012).

23. Strominger, J. L., Park, J. T. \& Thompson, R. E. Composition of the cell wall of Staphylococcus aureus: its relation to the mechanism of action of penicillin J. Biol. Chem. 234, 3263-3268 (1959).

24. Bertozzi, C. R. \& Kiessling, L. L. Chemical glycobiology. Science 291, 2357-2364 (2001).

25. Sadamoto, R. et al. Cell-wall engineering of living bacteria. J. Am. Chem. Soc. 124, 9018-9019 (2002).

26. Liechti, G. W. et al. A new metabolic cell-wall labelling method reveals peptidoglycan in Chlamydia trachomatis. Nature 506, 507-510 (2014).

27. Kuru, E. et al. In Situ probing of newly synthesized peptidoglycan in live bacteria with fluorescent D-amino acids. Angew. Chem. Int. Ed. Engl. 51, 12519-12523 (2012)

28. Lebar, M. D. et al. Reconstitution of peptidoglycan cross-linking leads to improved fluorescent probes of cell wall synthesis. J. Am. Chem. Soc. 136, 10874-10877 (2014).

29. Gale, R. T. \& Brown, E. D. New chemical tools to probe cell wall biosynthesis in bacteria. Curr. Opin. Microbiol. 27, 69-77 (2015).

30. Siegrist, M. S. et al. (D)-Amino acid chemical reporters reveal peptidoglycan dynamics of an intracellular pathogen. ACS Chem. Biol. 8, 500-505 (2013).

31. Shieh, P., Siegrist, M. S., Cullen, A. J. \& Bertozzi, C. R. Imaging bacterial peptidoglycan with near-infrared fluorogenic azide probes. Proc. Natl Acad. Sci. USA 111, 5456-5461 (2014).
32. Tiyanont, K. et al. Imaging peptidoglycan biosynthesis in Bacillus subtilis with fluorescent antibiotics. Proc. Natl Acad. Sci. USA 103, 11033-11038 (2006).

33. Kocaoglu, O. et al. Selective penicillin-binding protein imaging probes reveal substructure in bacterial cell division. ACS Chem. Biol. 7, 1746-1753 (2012).

34. Daniel, R. A. \& Errington, J. Control of cell morphogenesis in bacteria: two distinct ways to make a rod-shaped cell. Cell 113, 767-776 (2003).

35. Nelson, J. W. et al. A biosynthetic strategy for re-engineering the Staphylococcus aureus cell wall with non-native small molecules. ACS Chem. Biol. 5, 1147-1155 (2010).

36. Garner, E. C. et al. Coupled, circumferential motions of the cell wall synthesis machinery and MreB filaments in B. subtilis. Science 333, 222-225 (2011).

37. Sadamoto, R. et al. Bacterial surface engineering utilizing glucosamine phosphate derivatives as cell wall precursor surrogates. Chemistry 14, 10192-10195 (2008).

38. Raymond, J. B., Mahapatra, S., Crick, D. C. \& Pavelka, Jr. M. S. Identification of the namH gene, encoding the hydroxylase responsible for the N-glycolylation of the mycobacterial peptidoglycan. J. Biol. Chem. 280, 326-333 (2005).

39. Hansen, J. M. et al. N-glycolylated peptidoglycan contributes to the immunogenicity but not pathogenicity of Mycobacterium tuberculosis. J. Infect. Dis. 209, 1045-1054 (2014).

40. Melnyk, J. E., Mohanan, V., Schaefer, A. K., Hou, C. W. \& Grimes, C. L. Peptidoglycan modifications tune the stability and function of the innate immune receptor Nod2. J. Am. Chem. Soc. 137, 6987-6990 (2015).

41. Gisin, J., Schneider, A., Nagele, B., Borisova, M. \& Mayer, C. A cell wall recycling shortcut that bypasses peptidoglycan de novo biosynthesis. Nat. Chem. Biol. 9, 491-493 (2013).

42. Ye, H. et al. A safe and facile route to imidazole-1-sulfonyl azide as a diazotransfer reagent. Org. Lett. 15, 18-21 (2013).

43. Dahl, U., Jaeger, T., Nguyen, B. T., Sattler, J. M. \& Mayer, C. Identification of a phosphotransferase system of Escherichia coli required for growth on $\mathrm{N}$-acetylmuramic acid. J. Bacteriol. 186, 2385-2392 (2004).

44. Uehara, T., Suefuji, K., Jaeger, T., Mayer, C. \& Park, J. T. MurQ Etherase is required by Escherichia coli in order to metabolize anhydro-N-acetylmuramic acid obtained either from the environment or from its own cell wall. J. Bacteriol. 188, 1660-1662 (2006).

45. Kahan, F. M., Kahan, J. S., Cassidy, P. J. \& Kropp, H. The mechanism of action of fosfomycin (phosphonomycin). Ann. N. Y. Acad. Sci. 235, 364-386 (1974).

46. Kolb, H. C., Finn, M. G. \& Sharpless, K. B. Click chemistry: diverse chemical function from a few good reactions. Angew. Chem. Int. Ed. Engl. 40, 2004-2021 (2001).

47. Gustafsson, M. G. et al. Three-dimensional resolution doubling in wide-field fluorescence microscopy by structured illumination. Biophys. J. 94, 4957-4970 (2008).

48. Adams, D. W. \& Errington, J. Bacterial cell division: assembly, maintenance and disassembly of the Z ring. Nat. Rev. Microbiol. 7, 642-653 (2009).

49. Rust, M. J., Bates, M. \& Zhuang, X. Sub-diffraction-limit imaging by stochastic optical reconstruction microscopy (STORM). Nat. Methods 3, 793-795 (2006).

50. Buss, J. et al. In vivo organization of the FtsZ-ring by ZapA and ZapB revealed by quantitative super-resolution microscopy. Mol. Microbiol. 89, 1099-1120 (2013).

51. Turner, R. D., Hurd, A. F., Cadby, A., Hobbs, J. K. \& Foster, S. J. Cell wall elongation mode in Gram-negative bacteria is determined by peptidoglycan architecture. Nat. Commun. 4, 1496 (2013).

52. Osawa, T. \& Jeanloz, R. W. An improved, stereoselective synthesis of 2-amino3-O-(D-1-carboxyethyl)-2-deoxy-D-glucose (muramic acid). J. Org. Chem. 30, 448-450 (1965).

53. Matsushima, Y. \& Park, J. T. Stereospecific synthesis of 2-amino-3-O-(D-1'carboxyethyl)-2-deoxy-D-glucose (muramic acid) and related compounds1,2. J. Org. Chem. 27, 3581-3583 (1962).

54. Ragoussis, V., Leondiadis, L., Livaniou, E. \& Evangelatos, G. P. A simple approach to the synthesis of muramic acid and isomuramic acid: $1 \mathrm{H}$ and $13 \mathrm{C}$ NMR characterisation. Carbohydrate Res. 297, 289-295 (1997).

55. Borisova, M. et al. Peptidoglycan recycling in Gram-positive bacteria is crucial for survival in stationary phase. mBio 7, e00923-e01016 (2016).

56. Tsui, H. C. et al. Pbp2x localizes separately from $\mathrm{Pbp} 2 \mathrm{~b}$ and other peptidoglycan synthesis proteins during later stages of cell division of Streptococcus pneumoniae D39. Mol. Microbiol. 94, 21-40 (2014).

57. de Pedro, M. A. \& Cava, F. Structural constraints and dynamics of bacterial cell wall architecture. Front. Microbiol. 6, 449 (2015).

58. Hayhurst, E. J., Kailas, L., Hobbs, J. K. \& Foster, S. J. Cell wall peptidoglycan architecture in Bacillus subtilis. Proc. Natl Acad. Sci. USA 105, 14603-14608 (2008).

59. Wang, S., Furchtgott, L., Huang, K. C. \& Shaevitz, J. W. Helical insertion of peptidoglycan produces chiral ordering of the bacterial cell wall. Proc. Natl Acad. Sci. USA 109, 595-604 (2012).

60. Scheffers, D. J. \& Pinho, M. G. Bacterial cell wall synthesis: new insights from localization studies. Microbiol. Mol. Biol. Rev. 69, 585-607 (2005). 
61. Baba, T. et al. Construction of Escherichia coli K-12 in-frame, single-gene knockout mutants: the Keio collection. Mol. Syst. Biol. 2, 1-11 (2006).

62. Konkol, M. A., Blair, K. M. \& Kearns, D. B. Plasmid-encoded ComI inhibits competence in the ancestral 3610 strain of Bacillus subtilis. J. Bacteriol. 195, 4085-4093 (2013).

63. Yasbin, R. E., Wilson, G. A. \& Young, F. E. Transformation and transfection in lysogenic strains of Bacillus subtilis: evidence for selective induction of prophage in competent cells. J. Bacteriol. 121, 296-304 (1975).

64. Falk, P. J., Ervin, K. M., Volk, K. S. \& Ho, H. T. Biochemical evidence for the formation of a covalent acyl-phosphate linkage between UDP-Nacetylmuramate and ATP in the Escherichia coli UDP-N-acetylmuramate: L-alanine ligase-catalyzed reaction. Biochemistry 35, 1417-1422 (1996).

65. Auger, G. et al. Large-scale preparation, purification, and crystallization of UDP-N-acetylmuramoyl-L-alanine: D-glutamate ligase from Escherichia coli. Protein Expr. Purif. 13, 23-29 (1998).

66. Zeng, B., Wong, K. K., Pompliano, D. L., Reddy, S. \& Tanner, M. E. A phosphinate inhibitor of the meso-diaminopimelic acid-adding enzyme (MurE) of peptidoglycan biosynthesis. J. Org. Chem. 63, 10081-10085 (1998).

67. Anderson, M. S., Eveland, S. S., Onishi, H. R. \& Pompliano, D. L. Kinetic mechanism of the Escherichia coli UDPMurNAc-tripeptide D-alanyl-D-alanineadding enzyme: use of a glutathione S-transferase fusion. Biochemistry 35, 16264-16269 (1996).

68. Dempsey, G. T., Vaughan, J. C., Chen, K. H., Bates, M. \& Zhuang, X. Evaluation of fluorophores for optimal performance in localization-based super-resolution imaging. Nat. Methods 8, 1027-1036 (2011).

69. Klein, T. et al. Live-cell dSTORM with SNAP-tag fusion proteins. Nat. Methods 8, 7-9 (2011).

70. van de Linde, S. et al. Direct stochastic optical reconstruction microscopy with standard fluorescent probes. Nat. Protoc. 6, 991-1009 (2011).

\section{Acknowledgements}

For financial support, this project was supported by the Delaware COBRE program, with a grant from the National Institute of General Medical Sciences-NIGMS P20GM10431601A1. C.L.G. is a Pew Biomedical Scholar and Cottrell Scholar, and thanks the Pew Foundation and the Research Corporation for Science Advancement. K.E.D. thanks the $\mathrm{NIH}$ for support through a CBI training grant: 5T32GM008550. For instrumentation support, the Delaware COBRE and INBRE programmes supported this project with a grant from the National Institute of General Medical Sciences-NIGMS (5 P30

GM110758-02, P20GM104316-01A1 and P20 GM103446) from the National Institutes of Health. We thank the Boyd Laboratory at the University of Delaware, specifically Nathan McDonald, for assistance with strain construction. We thank Papa Nii AsareOkai, the director of the MS facility in the Chemistry and Biochemistry Department at the University of Delaware, with assistance in MS. We thank Renee Dalrymple from Carl Zeiss for access and assistance with 3D-STORM.

\section{Author contributions}

H.L. contributed to the design of AmgK and MurU utility, and performed the in vitro protein expression, purification and bacterial growth studies. K.E.D. contributed to NAM probe and synthetic designs, and performed all syntheses, purifications and compound characterization work. C.L.G., H.L. and K.E.D. designed cell labelling experiments and H.L. conducted bacterial cell wall labelling. K.E.D. and H.L. imaged all bacteria samples with help from J.C. J.C. led H.L., K.E.D. and C.L.G. in STORM data analysis. K.E.D. and H.L., led by M.P., performed the flow cytometry analyses. M.P. provided the J774 macrophage cells, while C.W.H. was involved in the macrophage growth and maintenance, and with H.L. performed macrophage invasion. K.E.D., H.L. and C.W.H. performed macrophage cell imaging. C.L.G., H.L. and K.E.D. were involved in study design and C.L.G. guided research. C.L.G., K.E.D. and H.L. analysed all data and wrote the manuscript. H.L. and K.E.D. contributed equally to this work. All authors discussed and commented on the data in this manuscript.

\section{Additional information}

Supplementary Information accompanies this paper at http://www.nature.com/ naturecommunications

Competing interests: The authors declare no competing interests.

Reprints and permission information is available online at http://npg.nature.com/ reprintsandpermissions/

How to cite this article: Liang, H. et al. Metabolic labelling of the carbohydrate core in bacterial peptidoglycan and its applications. Nat. Commun. 8, 15015 doi: 10.1038/ ncomms15015 (2017).

Publisher's note: Springer Nature remains neutral with regard to jurisdictional claims in published maps and institutional affiliations.

(c) (i) This work is licensed under a Creative Commons Attribution 4.0 cc. International License. The images or other third party material in this article are included in the article's Creative Commons license, unless indicated otherwise in the credit line; if the material is not included under the Creative Commons license, users will need to obtain permission from the license holder to reproduce the material. To view a copy of this license, visit http://creativecommons.org/licenses/by/4.0/

C) The Author(s) 2017 